\title{
A 2D AERODYNAMIC STUDY ON MORPHING OF THE NACA 2412 AEROFOIL
}

\author{
Pratik Meghani $^{1}$ \\ ${ }^{1}$ School of Computing, Engineering and Mathematics \\ University of Brighton \\ Cockcroft Building, Lewes Road, Brighton, BN2 4GJ \\ www.brighton.ac.uk \\ United Kingdom
}

Keywords: Aerofoil, Morphing, XFOIL, CFD (ANSYS FLUENT), Wind Tunnel Testing

\begin{abstract}
This paper investigates the potential of modifications of the NACA 2412 aerofoil geometry which could be implemented as a morphing wing in the Cessna 172SP. A 2D study on three morphing configurations: landing, take-off and stall maneuvering was conducted. The new geometries were designed using XFLR5. The initial aerodynamics characteristics were computed using XFOIL and compared to that of NACA 2412 in the Cessna 172SP. A selected configuration (landing) was tested at the University of Brighton wind tunnel facility and comparison to XFOIL predictions. Moreover, the ESDU 07010 report was used to extrapolate the Reynold's number to full scale, which was necessary to obtain an approximation of the aerodynamic characteristics at actual flight. The paper presents results of ANSYS FLUENT simulations for all three configurations. Results reveal that XFOIL is suitable for morphing airfoil configuration analysis but only at low Reynolds number $(\operatorname{Re} \approx 500,000)$. Adaptive aerofoil geometry improves the lift to drag (L/D) ratio by decreasing the drag coefficient; it also expands the flight envelope by delaying stall.
\end{abstract}

\section{INTRODUCTION}

All modern fixed-wing aircrafts have an optimal window of aerodynamic performance. This implies that high lift devices such as flaps and slats have been used to alter the aerodynamic characteristics to suit the mission profile of any given aircraft, such as extending the flaps during landing. To increase the aerodynamic performance and efficiency at different flight conditions, morphing aerofoil configurations were considered. Morphing involves changing the aerofoil's geometry during flight to optimise the aerodynamic characteristics to achieve better performance. It increases the overall efficiency of a wing by reducing the drag, complexity of dynamic structures in high lift devices and overall scour. The performance of the morphing aerofoil was analysed using XFOIL and compared to wind tunnel experiments and Computational Fluid Dynamics (CFD) software. This study focuses only on the aerodynamic aspect of morphing wing and aspects such as material, manufacture and control are not included.

\section{STATE OF THE ART}

\subsection{Modern wing morphing technology}

General aircraft wing shape is optimised for selected flight condition and the opportunity for shape modifications which adapt to the flight conditions will be beneficial for aircraft performance. Typical 
HLD (High Lift Devices) are not designed to change the wing shape in other phases other than take-off and landing. Morphing wing could "replace" HLD in the landing and take-off configuration and also improve aircraft performance in other phases of flight due to "more flexible shape".

A morphing platform would increase the cost effectiveness of the aircraft by eliminating the necessity for multiple, expensive elements. Morphing has several advantages: it expands the flight envelope of the aircraft to increase its performance, reduces the overall drag and replaces the conventional trailing edge flap to improve flight performance and stealth. However, the cost involved to design and manufacture a morphing wing is high and such advanced materials are not readily available.

This study focuses only on the aerodynamic design. However, the problem of design and manufacture of a morphing wing is being investigated by other researchers. Research at FlexSys Inc. (in collaboration with Air Force Research Labs) investigates into introducing compliant mechanisms as a potential technology to varying the leading and trailing edge surface. The monolithic structures used rely on elastic deformation of its constituent elements to transmit motion. [1]. Their demonstration wing performs large controlled deformations (from $-9^{\circ}$ to $+40^{\circ}$ ) needed for landing and take-off. Practical benefits of exploiting compliant material structures include:

a) Reduced complexity of dynamic structures in high lift devices.

b) Sub-micron accuracy

c) Embedded sensing and actuation.

d) Zero backlash and wear.

NASA and MIT have a collaboration project where the wings are cloaked in a 'skin' made of overlapping layers like scales or feathers (composite cellular material). The structure is therefore flexible and has a smoother aerodynamic surface. This skin is made from $0.127 \mathrm{~mm}$ thick kapton (polyimide film) which is cut into strips with hole patterns. The next stage of this project will be a study into the application of this system for the entire frame of the wing. [2]

A new form of discontinuous morphing could be considered as an effective option for a wing structure. It is formed by individual, rigid segments without shared or continuous skin. These segments are pivoted around a main spar effectively changing non-linear wing twist. This design has great potential to create span-wise lift and drag distribution for performance optimisation. Its construction consists of a multi-flap control system and integrates all control function (pitch, roll and yaw) with continuous performance optimisation by changing multipoint wing twist distribution. [3]

\section{MORPHING CONFIGURATIONS AND PRELIMINARY ANALYSIS}

The first phase of this project was redesigning the Cessna 172SP aerofoil geometry. The geometry modification tool in XFLR5 was utilised to alter the NACA 2412 aerofoil's geometry to obtain three ideal configurations for each condition (take-off, landing and stall manoeuvre). XFLR5 is an analysis tool for aerofoils, wings and planes operating at low Reynolds numbers. The software includes XFOIL's Direct and Inverse analysis capabilities and wing design and analysis potential based on the Lifting-line Theory, the Vortex Lattice Method and on a 3D Panel Method. The XFOIL code was then applied to several designs of each configuration before a suitable one was chosen.

\subsection{The XFOIL code}

XFOIL uses a fast and robust analysis method for on-design and off-design performance evaluation. Its mathematical algorithm handles very strong and nonlinear coupling between the viscous, transition and inviscid formulations at separation bubbles. XFOIL's viscous formulation is similar to that of the transonic ISES code. In this method, the Euler equations are discretised on a conservative streamline 
grid and are coupled to a 2-equation integral boundary layer formulation, using the displacement thickness concept. A transition prediction formulation of $\mathrm{e}^{\mathrm{N}_{-} \text {crit }}$ is incorporated into the viscous formulation. The discrete equation set (viscous and transition formulations) is solved as a fully coupled nonlinear system by a global Newton method. The Newton method is rapid and reliable for dealing with strong viscous-inviscid interactions which occur at low Reynolds number (Re) flows (about half a million). An N_crit value of 9 (default) and a turbulence factor of 0.0759 was applied to all simulations in XFOIL and was calculated using equation (1). [4]

$$
N_{\text {crit }}=-8.43-2.4 \ln (\mathrm{Tu} \% / 100 \%)
$$

There are not many published papers that focus purely on an aerodynamic approach on morphing at high Re using either XFOIL or any valid CFD software; however, a journal paper named - XFOIL vs CFD performance prediction for high lift low Reynold's number airfoils - was found valuable. [5]

In this literature, Blade Element Momentum theory (BEM) was used to calculate the performance of propellers using Reynolds Averaged Navier Stokes (RANS) equations ( $k-\omega$ SST and k-kl-I) and inviscid flow coupled with boundary layer formulation. The results showed that all predictions were in good agreement with the experiments and concluded that XFOIL was an excellent aerofoil design and analysis tool at low $\operatorname{Re}\left(2.0 \times 10^{5}\right)$.

\subsection{Config-1: Landing with full flaps $\left(30^{\circ}\right)$ at $\operatorname{Re}$ of 596,610}

This layout consisted of a fish-bone tail structure that could flex to resemble a flap mechanism. Config1 was analysed at this Re in specific to compare the results with the wind tunnel test conducted. The test Re would later be extrapolated to actual flight conditions. The XFOIL simulation of Config-1 indicated a clear improvement in the L/D ratio (low $C_{D}$ ) in comparison to a conventional $30^{\circ}$ flap. The flap was located at $70 \%$ of the chord length and the traditional flap data was obtained from XFOIL simulation. Figure 1 shows the $L / D$ and $C_{D}$ comparison of Config- 1 and the conventional flap.

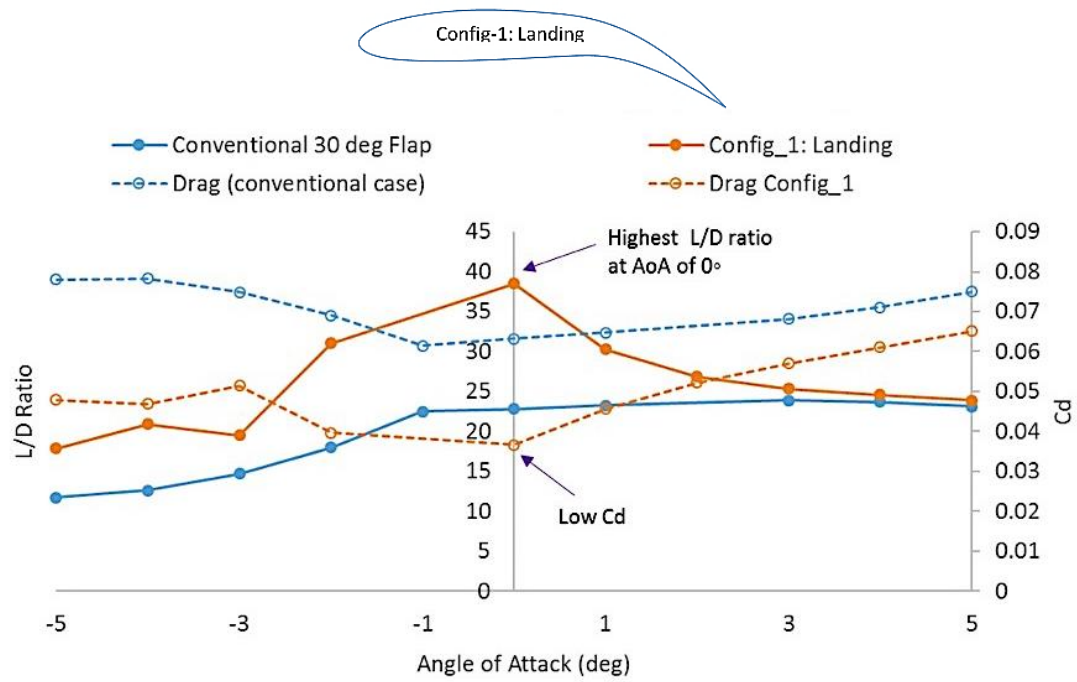

Figure 1: Conventional NACA $241230^{\circ}$ Flap vs Config-1

\subsection{Config-2 and Config-3: Take-off and Stall Manoeuvre respectively at Re of 3,492,402}

Config-2 exhibited a drooping leading-edge feature which was designed to exhibit better aerodynamic characteristic during take-off/climb, hence the range of Angle of Attack (AoA) from $7^{\circ}$ to $15^{\circ}$. The XFOIL simulations performed reflected this, hence high $L / D$ ratio due to low coefficient of drag between this ranges. 
Config_3 incorporated a droop and active fish-bone like feature on the leading edge and trailing edge respectively. The purpose of designing this aerofoil was to exploit the aerodynamic limit via morphing. This could be beneficial in training aircrafts by giving new pilots more time to react before stall. XFOIL simulations predicted an increase in stall angle from $18^{\circ}$ to $23^{\circ}$. Figure 2 show the L/D comparison of Config-2 \& 3 and the NACA 2412 computed using XFOIL.

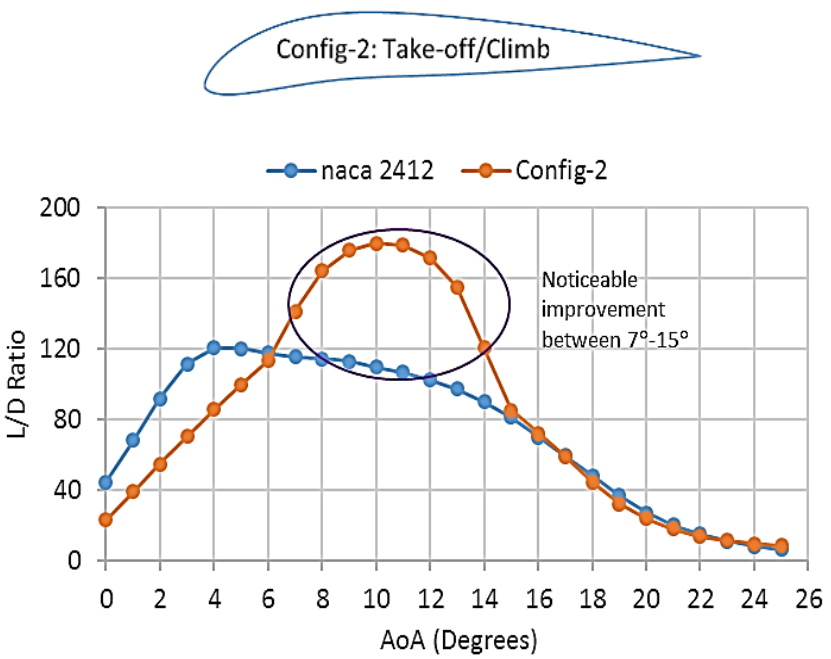

(a)

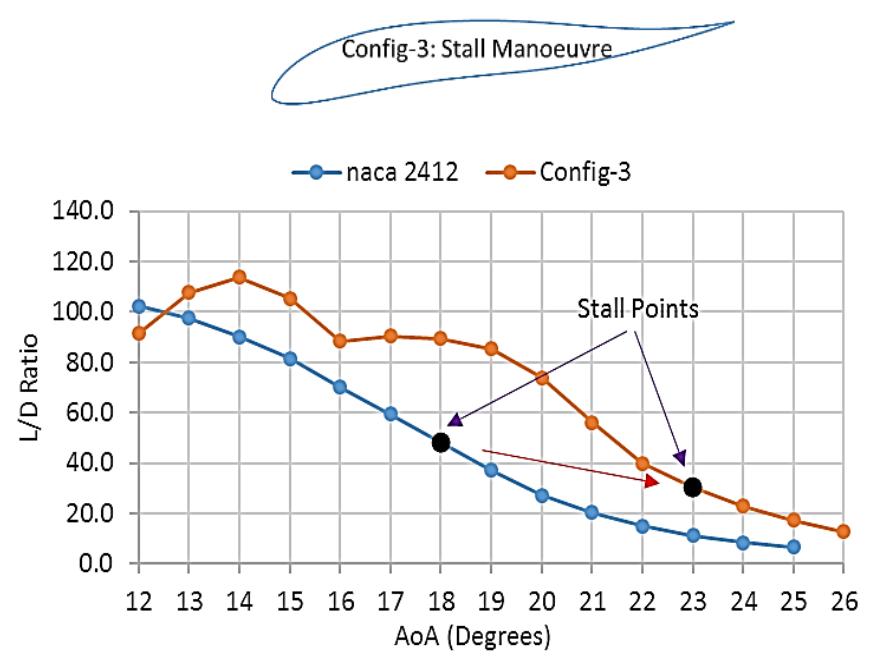

(b)

Figure 2: (a) XFOIL Comparison of Config-2 vs NACA 2412 (b) XFOIL Comparison of Config-3 vs NACA 2412

\section{WIND TUNNEL TEST}

This section of the research paper presents the wind tunnel test results for the model scale of Config1. As mentioned in section 3.1, the Re would be extrapolated from the wind tunnel test to full scale flight using the transition-location 'sweep' presented in the ESDU 07010 technical paper [6]. The main purpose of the experiment was to conduct a 2D pressure distribution study of the airflow over the surface of the model; in comparison to XFOIL results.

\subsection{Wind tunnel - 2D Pressure Profile study}

The research was conducted at the open section closed circuit subsonic wind tunnel at the University of Brighton. A paraffin-filled manometer was utilised to measure pressure. Pressure tapings on the surface of the model determined the pressure coefficient distribution. The test was carried out for AoA from $-5^{\circ}$ to $5^{\circ}$ and free stream speed equal to $V=22 \mathrm{~m} / \mathrm{s}$, which correspond to $\operatorname{Re}=596,610$. 


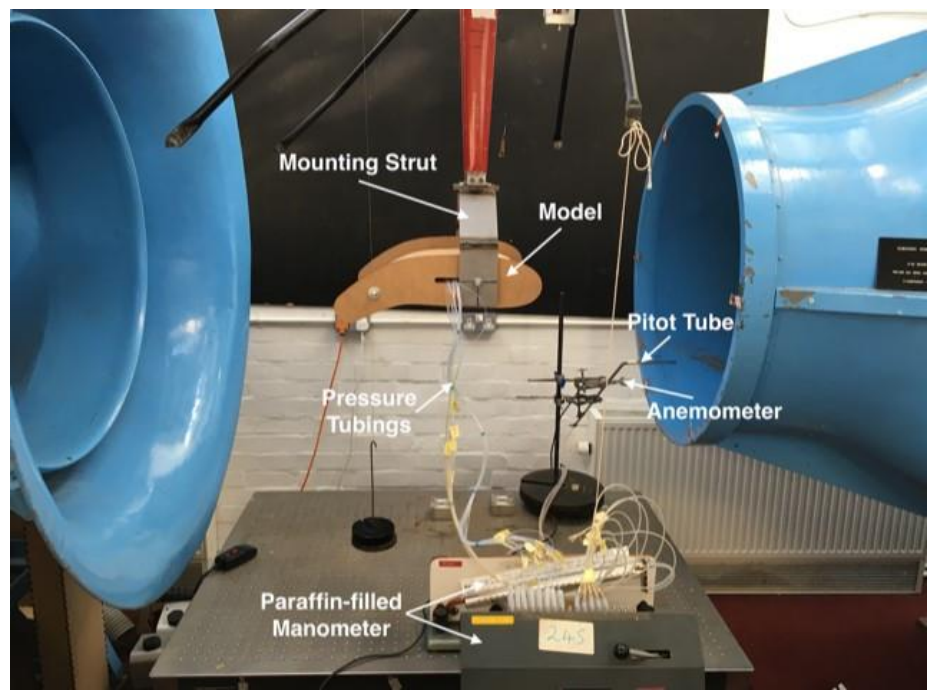

Figure 3: Wind Tunnel Setup

\subsection{Model}

The model was constructed in 1:4 scale with a chord length of $0.4 \mathrm{~m}$ and a width of $0.45 \mathrm{~m}$. It was composed of a 3-piece structure with the centre piece containing the pressure tapings. Figures 4 to 5 present the stages in the manufacturing process.
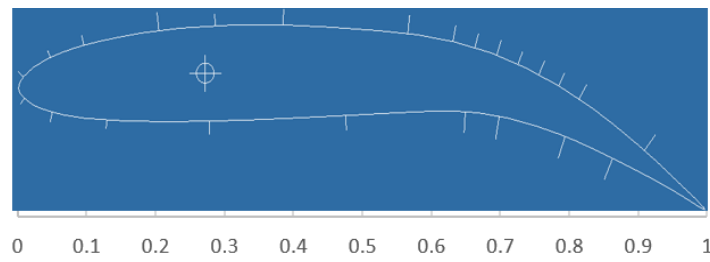

(a)

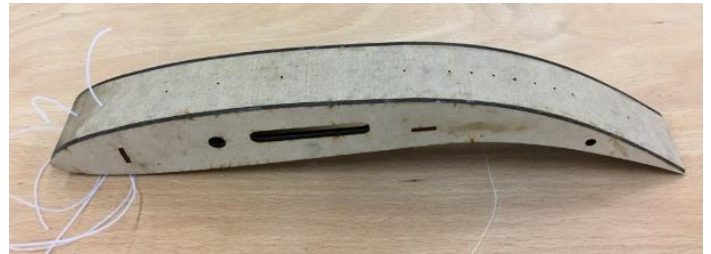

(b)

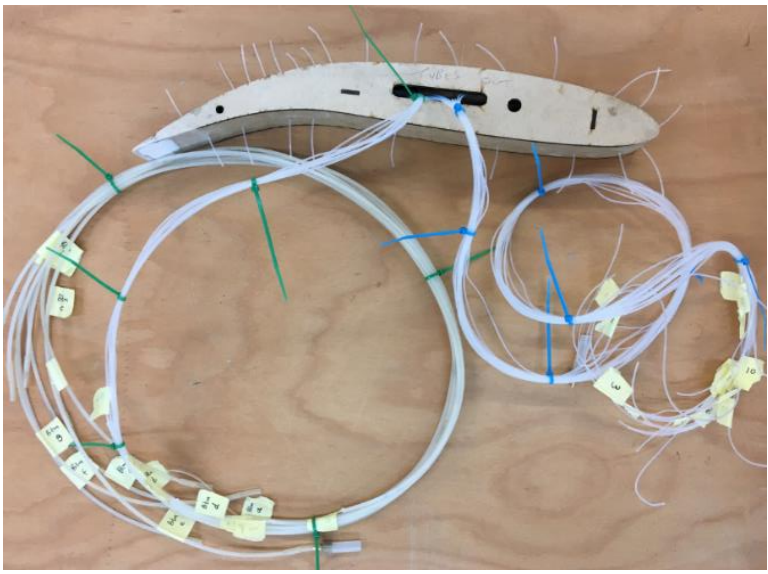

(c)

Figure 4: (a) Pressure taping locations (b) Upper surface of model showing $1 \mathrm{~mm}$ taped holes (c) Complete centre piece with labelled pressure tubing

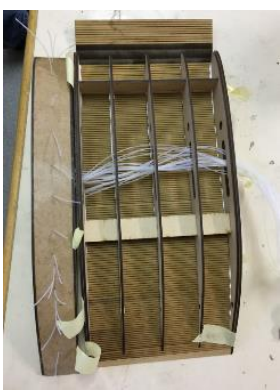

(a)

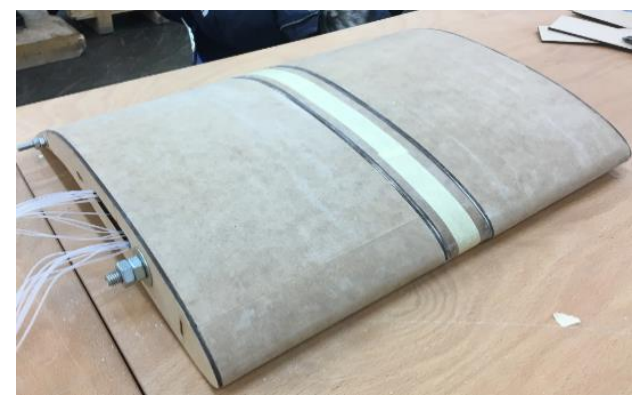

(b)

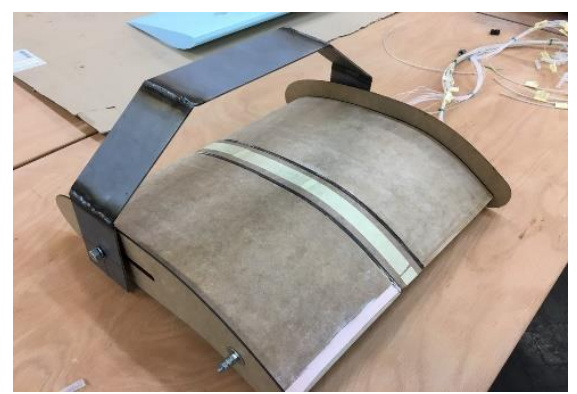

(c)

Figure 5: (a) Laying skin over adjoining section (b) Smoothened model fastened with $10 \mathrm{~mm}$ studding (c) Complete test model with mounting strut 


\subsection{Results}

The coefficient of lift $\left(C_{L}\right)$ was calculated based on the pressure coefficient. Equations (2) and (3) were used to calculate the $C_{L}$ for this case. The results presented show a comparison of the $2 \mathrm{D}$ pressure distribution between the wind tunnel test and the initial XFOIL predictions for 3 tests ranging from an AoA from $-5^{\circ}$ to $5^{\circ}$.

$$
\begin{gathered}
C_{P}=\frac{\Delta P}{\frac{1}{2} \cdot v^{2} \cdot \rho} \\
C_{L}=\int_{0}^{y} C_{P} \times \operatorname{Cos}(\alpha)
\end{gathered}
$$

Comparison of XFOIL and experimental results for Test A, B and C are presented in Table 1. Figure 6 presents the comparison of the 2D pressure profiles between XFOIL and the experiment for the scale model of Config-1.

\begin{tabular}{lcccccc}
\hline & \multicolumn{2}{c}{ Test $A\left(-5^{\circ}\right)$} & \multicolumn{2}{c}{ Test $B\left(0^{\circ}\right)$} & \multicolumn{2}{c}{ Test C $\left(5^{\circ}\right)$} \\
\hline & $C_{D}$ & $C_{L}$ & $C_{D}$ & $C_{L}$ & $C_{D}$ & $C_{L}$ \\
\hline XFOIL Prediction & 0.024 & 0.251 & 0.038 & 0.620 & 0.047 & 0.987 \\
Wind Tunnel Test & 0.033 & 0.275 & 0.025 & 0.700 & 0.082 & 1.071 \\
\hline
\end{tabular}

Table 1: Comparison of aerodynamic data between XFOIL and Wind Tunnel Test

TEST A [AOA of $\left.-5^{\circ}\right]$

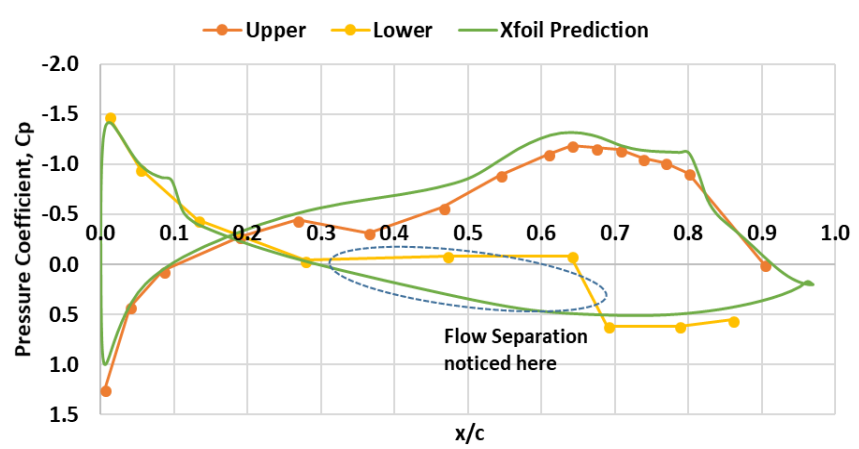

(a)

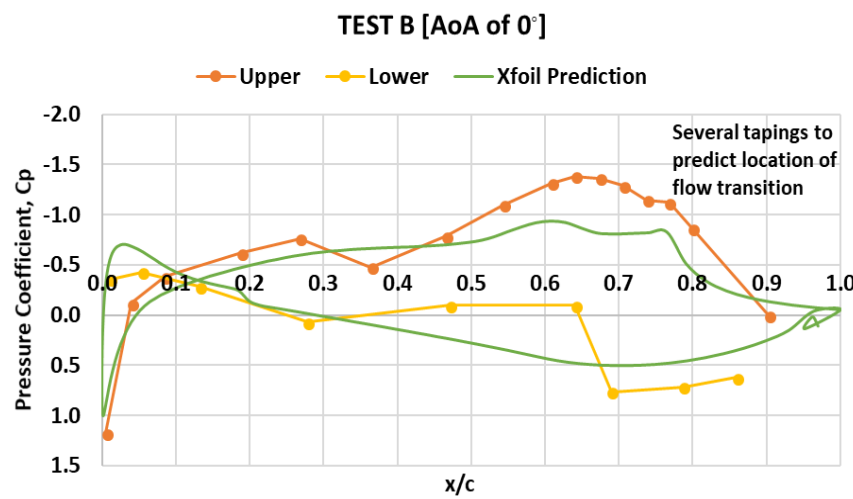

(b)

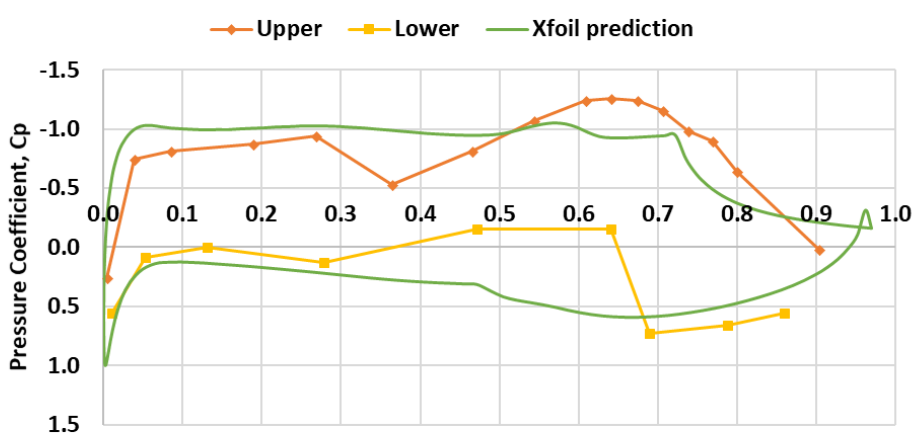

$\mathrm{x} / \mathrm{c}$

Figure 6: (a) Cp vs $x / c$ Test $A$ (b) Cp vs $x / c$ Test $B$ (c) Cp vs $x / c$ Test $C$ 


\subsection{Reynold's number extrapolation for Test B}

Assuming the stagnation conditions in the wind tunnel were fixed ('atmospheric tunnel'), the transition-location 'sweep' extrapolation method was used to extrapolate the Reynolds number to real flight conditions. This involved manipulating the boundary layer state at the test Reynolds number to reproduce flow features that occur at higher Reynolds number. Control over the boundary layer state was achieved by moving the transition roughness strip from the position corresponding to fullscale transition (near leading edge) to a point further aft (aft-fixing). Moving the transition location aft thins the turbulent boundary layer, thus simulating flow at high Reynolds number. This enables a chosen flow feature, e.g. the boundary layer momentum thickness at the wing trailing edge, to be matched. To apply this extrapolation method to an aerofoil, the flat plate criterion was used in Reynolds number mapping and based on the assumption of an incompressible boundary layer. [6] The momentum thickness at the trailing edge of the flat plate was matched using empirical relationships for local surface friction coefficient and boundary layer theory. Equation (4) and (5) show the mapping function.

$$
\begin{gathered}
\frac{x_{o}}{c}=\frac{x_{t r}}{c}-41.58 R e_{\text {test }}^{-3 / 8}\left(\frac{x_{t r}}{c}\right)^{5 / 8} \\
\frac{R e_{\text {eff }}}{R e_{\text {test }}}=\left(1-\frac{x_{o}}{c}\right)^{-4}=\left(1-\frac{x_{t r}}{c}-41.58 \operatorname{Re}_{\text {test }}^{-3 / 8}\left(\frac{x_{\text {tr }}}{c}\right)^{5 / 8}\right)^{-4}
\end{gathered}
$$

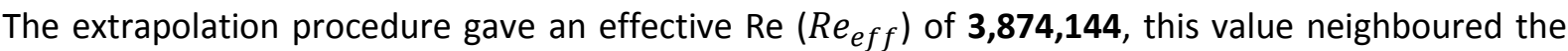
expected Re of $\mathbf{3 , 9 4 2 , 5 0 5}$. The transition distance $\left(x_{t r}\right)$ was based on XFOIL's prediction and was obtained as $\mathbf{0 . 2 2 9 7} \mathrm{m}$. Assuming that the test was conducted above the critical Reynold's number, similar aerodynamic characteristics were expected to be seen in actual flight as observed in the scale model testing.

\section{NUMERICAL CALCULATION}

Numerical aerodynamic calculations were applied to the other morphing configurations (Config-2 \& Config-3) at full scale ( $\mathrm{c}=1.6 \mathrm{~m}$ ) in comparison to XFOIL and NACA 2412 in Cessna 172SP. FLUENT software (solves Navier-Stokes equations) was used for the research. Due to the size of the University of Brighton wind tunnel, there was no possibility to experimentally test those configurations, hence use of a scaled model.

\subsection{Fluent Simulation}

The flow domain area used was 20 times larger ( $32 \mathrm{~m}$ by $32 \mathrm{~m}$ ). Projection surfaces were created in preparation for meshing. The mesh element size was limited to $\leq 500,000$ to cut down simulation times. A triangular mesh was applied to all configurations with the element size (in the projection surface) increasing proximity to the given morphing configuration. 5 Inflation layers with a first layer thickness corresponding to the calculated $y+$ parameter was applied to the configurations.

All configurations were simulated in FLUENT, only Config-1 was a scaled model to ensure easy comparison with wind tunnel results. Table 2 describes the setup procedure used to perform the CFD simulations. 


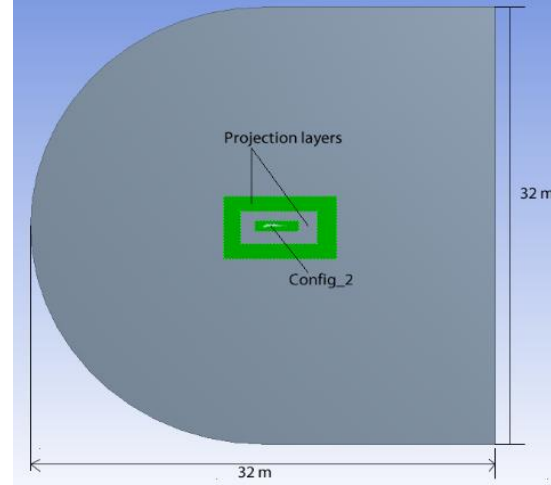

(a)

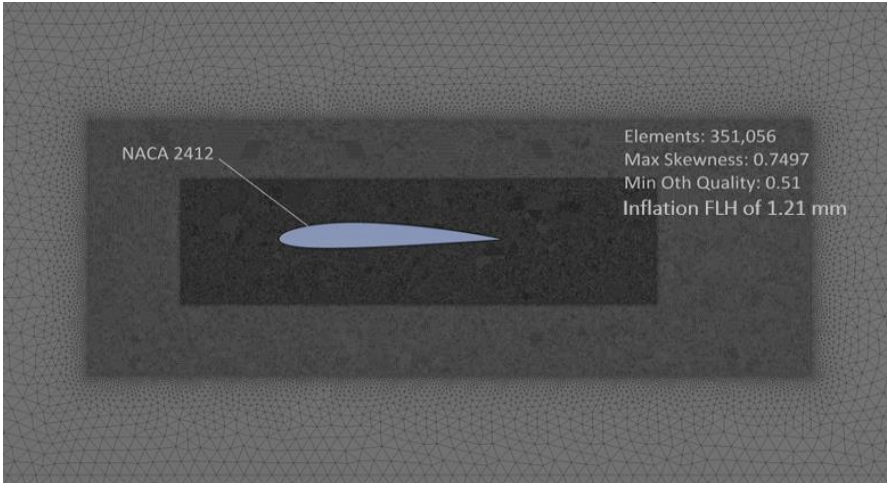

(b)

Figure 7: (a) Flow Domain area with projection surfaces (b) NACA 2412 mesh

\begin{tabular}{lcccc}
\hline & Config-1 & Config-2 & Config-3 & NACA 2412 \\
\hline Viscous Model & $\mathrm{k}-\varepsilon$ & $\mathrm{k}-\omega$ & $\mathrm{k}-\omega$ & $\mathrm{k}-\omega$ \\
Air Density $\left(\mathrm{Kg} / \mathrm{m}^{3}\right)$ & 1.2231 & 1.225 & 1.225 & 1.225 \\
Absolute Pressure $(\mathrm{Pa})$ & 101,678 & 101,325 & 101,325 & 101325 \\
Temperature $(\mathrm{K})$ & 289.65 & 288.15 & 288.15 & 288.15 \\
Inlet Velocity $(\mathrm{m} / \mathrm{s})$ & 22 & 31.89 & 31.89 & 31.89 \\
Reynold's Number & 596,610 & $3,492,402$ & $3,492,402$ & $3,492,402$ \\
AoA $\left({ }^{\circ}\right)$ & 0 & 0 to 28 & 16 to 34 & 0 to 28 \\
Convergence Criteria & $1.0 \mathrm{e}-3$ & $1.0 \mathrm{e}-6$ & $1.0 \mathrm{e}-5$ & $1.0 \mathrm{e}-5$ \\
\hline
\end{tabular}

Constant Parameters for all Simulations

Solver Characteristics

Pressure - Based

Turbulent Intensity (\%) and Length (m)

Solution Scheme

$2 \%$ and $0.001 \mathrm{~m}$ respectively

Reference Computation

\section{SIMPLE}

From Inlet

Table 2: FLUENT Setup

The use of the k- $\varepsilon$ model was based on a journal named - Low Reynolds number k-epsilon model for unsteady turbulent boundary-layer flows, [6] the k-omega model was not suitable for the simulation due to convergence difficulties.

By aiming for a $y+$ for 50 , the first layer cell height was calculated as $1.20771 \mathrm{~mm}$ for all the CFD simulations.

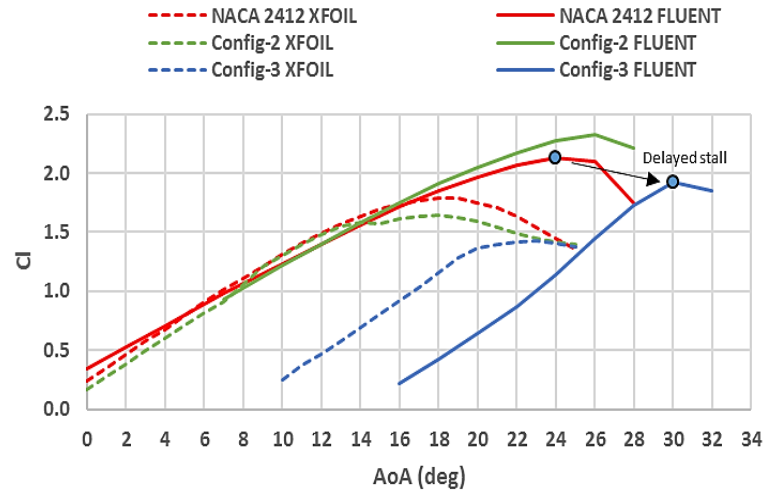

(a)

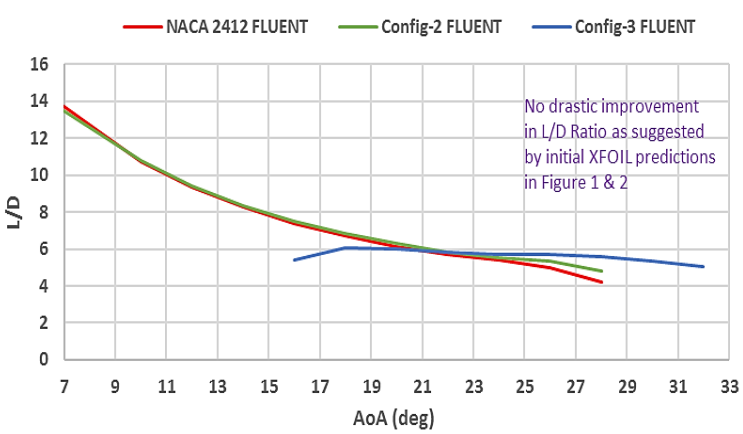

(b)

Figure 8: (a) Initial XFOIL predictions vs FLUENT at RE of 3,942,402 (b) L/D comparison in FLUENT 


\subsection{Results}

During the comparison study, the XFOIL results did not match with FLUENT at high Reynold's number $(3,492,402)$ as shown in Figure 8. There was a noticeable delay in the stall AoA attained by Config_3, as predicted by XFOIL. The trend in $C_{D}$ (low) was observed in both XFOIL and FLUENT. However, the value of the lift coefficient slope was similar up to an AoA of $18^{\circ}$ before a disparity of $25 \%, 33 \%$ and $44 \%$ in Config-3, Config-2 and NACA 2412 respectively. The aerodynamic coefficients were obtained from the pressure tubing only.

As a result, Test $B$ (wind tunnel test of Config- 1 at $0^{\circ}$ ) was simulated in FLUENT to compare three sets of data (wind tunnel test, XFOIL and FLUENT).

\begin{tabular}{lcc}
\hline & $C_{D}$ & $C C_{L}$ \\
\hline XFOIL & 0.03774 & 0.6204 \\
Wind Tunnel Experiment & - & 0.8235 \\
Wind Tunnel FLUENT & 0.03266 & 0.6214 \\
\hline
\end{tabular}

Table 3: XFOIL comparison with FLUENT for Wind Tunnel Test B at Re of 596,610

The $C_{L}$ and $C_{D}$ values obtained from FLUENT were as good as XFOIL's prediction at Re of 596,610. This proves Mark Drela's (initiator of XFOIL) remarks that the software is suitable for low Re (about half a million). It would be advantageous to increase the number of pressure tapings to obtain a better pressure distribution and to accurately predict $\mathrm{C}_{\mathrm{L}}$.

\section{CONCLUSIONS}

XFOIL is a suitable tool to simulate adaptive aerofoil geometry other than the conventional aerofoil profiles like the NACA and Clark Y series. Particular attention was given to extreme cases (Config-1) where an offset in the AoA was calculated in order for the pressure distribution to match the experimental results. For the adaptive aerofoil, XFOIL calculated the AoA conventionally using the chord length and the relative motion vector, hence giving orthodox results.

There was significant separation noticed at $20 \%$ of the chord during the wind tunnel test. Neither XFOIL nor FLUENT showed this phenomenon. The cause of this issue could be down to the build quality of the model i.e. the $2 \mathrm{~mm}$ MDF skin (highly scored) was difficult to bend around the leading edge, slightly modifying the geometry. The mounting strut (hang system) might have also played a role in influencing the overall aerodynamic study despite the guide string exhibiting steady characteristics during the wind tunnel test. The drag force associated with the hang system fluctuated $(1.925 \mathrm{~N} \pm 20 \%)$ due to the high uncertainty of the load cell balance of the wind tunnel.

XFOIL closely predicted the aerodynamic characteristics of the scaled model wind tunnel test at low Reynold's number (around 500,000). At higher Re $\left(3 \times 10^{6}\right)$, XFOIL results were invalid for full scale flow. To depict actual flow, a valid CFD software would be recommended after a comprehensive analysis between two or more viscous models.

This paper was part of a final year undergraduate project, hence only specific conditions (i.e. Full $30^{\circ}$ flaps at landing, take-off and stall) were prioritised due to project time considerations. It would be advantageous to optimise the adaptive aerofoil for a given range of airspeeds, for example, landing with flaps $\left(10^{\circ}, 20^{\circ}\right.$ or $\left.30^{\circ}\right)$ between 65 to 75 knots. It would be valuable to apply the morphing configurations to the Cessna 172SP wing to understand the performance in comparison to the 2D case study in this paper. Comparing the results of different viscous turbulent models would be advantageous in enumerating the uncertainty in the results obtained of the CFD study. 
Morphing technology could be integrated with control theory [8] to optimise the flight performance for any given condition. Delaying the stall could be a useful safety feature as the Cessna 172SP is widely used as a training aircraft for new generation of pilots.

\section{ACKNOWLEDGEMENTS}

I would like to thank the University of Brighton for funding our trip to the Czech Republic and giving us an opportunity to present our research paper at an undergraduate level and represent the university at this international conference. I also acknowledge the support my supervisor and the lab technicians gave in terms of technical advice and manufacturing expertise during the scale model construction.

\section{REFERENCES}

[1] Kota, S. (n.d.). Mission Adaptive Compliant Wing - Design, Fabrication and Flight Test. [online] (1), p.4. Available at: https://pdfs.semanticscholar.org/c894/116f99834e6aaeb181e40e8ef747132356ea.pdf [Accessed 15 Dec. 2017].

[2] NASA. (2018). Go, Go, Green Wing! Mighty Morphing Materials in Aircraft Design. [online] Available at: https://www.nasa.gov/ames/feature/go-go-green-wing-mighty-morphingmaterials-in-aircraft-design [Accessed 26 Apr. 2018].

[3] Tarnowski, A. (2017). Morphing wing with skin discontinuity - kinematic concept. Aircraft Engineering and Aerospace Technology, 89(4), pp.535-546.

[4] Web.mit.edu. (2018). An Analysis and Design System for Low Reynolds Number Airfoils. [online] Available at: http://web.mit.edu/drela/Public/papers/xfoil_sv.pdf [Accessed 3 Apr. 2018].

[5] Morgado, J., Vizinho, R., Silvestre, M. and Páscoa, J. (2016). XFOIL vs CFD performance predictions for high lift low Reynolds number airfoils. Aerospace Science and Technology, 52, pp.207-214.

[6] Philpott, D. (2007). Extrapolating wind-tunnel data to full-scale Reynolds number. ESDU, (07010), pp.13-14, 57-59.

[7] Fan, S., Lakshminarayana, B. and Barnett, M. (2018). Low-Reynolds-number k-epsilon model for unsteady turbulent boundary-layer flows. [online] Ntrs.nasa.gov. Available at: https://ntrs.nasa.gov/search.jsp?R=19930069211 [Accessed 11 Oct. 2018].

[8] Bourdin, P., Gatto, A. and Friswell, M. (2008). Aircraft Control via Variable Cant-Angle Winglets. Journal of Aircraft, 45(2), pp.414-423.

\section{COPYRIGHT STATEMENT}

The authors confirm that they, and/or their company or organization, hold copyright on all of the original material included in this paper. The authors also confirm that they have obtained permission, from the copyright holder of any third party material included in this paper, to publish it as part of their paper. The authors confirm that they give permission, or have obtained permission from the copyright holder of this paper, for the publication and distribution of this paper as part of the READ 2018 proceedings.

This is an open access article distributed under the Creative Commons Attribution License which permits unrestricted use, distribution, and reproduction in any medium, provided the original work is properly cited. (CC BY 4.0). 